\title{
AvóDezanove e o segredo do soviético: Janelas do tempo
}

\author{
Andrea Cristina Muraro \\ Universidade de São Paulo-CAPES.
}

Somos feitos da matéria dos sonhos;

nossa vida pequenina

é cercada pelo sono.

(Shakespeare. "A Tempestade". Ato IV, Cena I)

ando continuidade aos desdobramentos de seu projeto literário, em 2008 o escritor angolano Ondjaki coloca a público a narrativa AvóDezanove e o segredo do soviético. ${ }^{1}$ Desdobramento, já que não é difícil notar como esta obra enlaçase a Os da minha rua (2006) e Bom dia camaradas (2000), como que a tecer uma rede, fazendo marcar em seus nós algumas estratégias discursivas já recorrentes em sua produção.

Dentre elas, pode-se ressaltar o refinado uso de construções em paratexto, isto é, o preenchimento de espaços metalinguísticos como o da epígrafe que desencadeia diálogos semanticamente afins com o que será lido ao longo do texto, colocando-se em ressonância Clarice Lispector, Ana Paula Tavares, entre outras convocações que autenticam o autor em meio a uma comunidade que incorpora um certo grupo de escritores dos países de língua portuguesa. Mas não só: pode-se entrever ecos de Miguel de Cervantes (cf. "moinhos do tempo", p. 81) e Gabriel García Márquez em meio à narrativa.

Para compor as primeiras páginas, o autor convoca um trecho do Livro das aprendizagens, de Clarice Lispector, no qual a palavra "azul” é anunciada para

1 ONDJAKI. AvóDezanove e o segredo do soviético. Lisboa: Caminho, 2008. [São Paulo: Cia. das Letras, 2009]. 
um: "faz de conta que [é] a infância" (p. 4); a estória dá-nos logo o epílogo antecipado e suspenso como uma clara resposta à epígrafe:

Quer dizer, nunca ninguém fala das crianças, está bem que a nossa vida ainda é pequenina, mas nós também gostamos muito da PraiaDoBispo e os maisvelhos sempre se esquecem que quando há problemas nós podemos ajudar a resolver (2008, p. 113).

Atrás das obras, do lado de lá do nosso largo, ali onde a poeira não conseguia nunca aterrar, ficava essa coisa linda que todos dias me ensinava a cor azul: o mar grande, mais conhecido por oceano (p. 12).

O verbo "ensinar" pensado ao lado do título do livro de Clarice Lispector revela uma das dimensões da palavra azul: para o menino-narrador, pensar Luanda é pensar este azul nas suas variações, é aprender/prender a cidade a partir de uma cor, cujo percurso sensorial pode-se refazer, deambulando pelas linhas ao longo da Praia do Bispo.

Seguindo a palavra azul no texto, esta referência ao mar ainda mais parece a pele de um corpo que, ao bordejar a cidade, protege-a, tornando-se o seu órgão maior: "e então todos ficamos só a olhar o azul-escuro dele: na pele bem enorme do mar, com a IlhaDoMussulo lá do outro lado" (p. 20). Não só o menino-narrador é enlaçado pelo azul, mas também a avó, personagemtítulo: "olhava a nossa PraiaDoBispo com o mar lá no fundo a ensinar as cores do azul que chamam de marinho" (p. 119).

Através das personagens envolvidas no conflito narrativo de forma indireta - como "o VelhoPescador [que] aparecia com o Barcoĺris todo pintado de azul novinho e desde a casa da AvóDezanove até ao mar era um montão de areia que nunca tinha conhecido o cimento das obras do Mausoléu" (p. 118) - nota-se a tensão social e narrativa provocada pela construção do Mausoléu (ou Foguetão como o nomeiam as crianças) do presidente Agostinho Neto. E é na tensão que se inscrevem alguns motivos narrativos, como a presença dos soviéticos em Luanda para a execução das obras e que acabam por funcionar como pontos de azul em um mapa - desejados, ironizados ou não, os soldados são chamados de "formigas" ou "lagostas azuis"; destaque-se entre 
eles o soviético do título: CamaradaBotardov ou Bilhardov que: " Só ria, com a boca e com os olhos dele azuis muito cianos" (p. 31).

Outras personagens ajudam o narrador-menino a percorrer a infância azul em Luanda, como o motorista SenhorOsório, que em seu carro tem na ignição uma "luz azul linda" (p. 82), que estará acesa enquanto conduz o menino e a avó, da PraiaDoBispo ao cemitério do AltoDasCruzes, do cemitério ao HospitalMilitar.

Algumas das formas do azul são inusitadas, como quando a personagem que trabalha na casa da avó do narrador, MadalenaKamussekele, "deixava as penas [dos jacós] com gotas dessa água de restos de sabão azul, eles lambiam o corpo e ficavam quietos a não falar nada" (p. 162). E se os papagaios da casa da avó se calam diante da espuma azul, ou melhor, suspendem os "disparates" que repetem da Rádio Nacional e de filmes ou novelas de televisão com "plástico azul no ecrã" (p. 53), os papagaios/jacós engaiolados pelo CamaradaDimitri não cessam o seu

gritar "um só povo, uma só nação" e "de Luanda, capital da República Popular de Angola, transmite a Rádio Nacional”, com uma voz igualita ao camarada da Rádio que todos os dias dizia isso no noticiário das 13 e das 20 (p. 46).

Contudo, a repetição torna-se estratégia; repetir é acumular vozes, tempos e espaços:

todas as estórias que tínhamos visto e inventado, mais as que eram contadas, recontadas e aumentadas pelo EspumaDoMar,(...), estórias de kiandas que também são sereias que o VelhoPescador disse que viu mas outros dizem que não pode ter visto, estórias em kimbundu da AvóMaria que não entendemos nada até hoje porque na escola nunca nos ensinaram a falar nem escrever kimbundu, estórias do próprio camarada VendedorDeGasolina quando bebe e fala de mais, estórias do SenhorTuarles que fala pouco mas que afinal tem boas estórias do tempo de antigamente, estórias da AvóCatarina que abre e fecha janelas e muita gente anda a dizer que nós as crianças falamos à toa, que ela já não está lá em casa da minha AvóNhé, (...), estórias da PraiaDoBispo no tempo dos tugas, com menos poeira que agora e as pessoas parece que falavam diferente mas também o país era afinal ocupado e sem a independência da dipanda, 
e ainda, para não dizerem que esqueci, as estórias todas que a AvóDezanove me conta, tantas, com tantos nomes, com tanta gente e roupas, com danças e pianos e fados e viagens e casos, com falas e pensamentos e os carinhos e as pausas de silêncio que também fazem parte das estórias de depois do almoço que ela me conta, e tudo isso, às vezes, tantas vezes, não sei porquê, faz os maisvelhos pensarem que nós não vamos lembrar de tudo - (p. 116).

Recorre-se à memória conectada a cada frase rizomaticamente pelas conjunções "que" e "se", formando janelas que se fecham e se abrem: através delas, ouvem-se os missossos das avôs, as makas do bairro, as estigas entre as crianças, o mujimbo sobre a explosão da PraiaDoBispo.

Como exemplo dessas janelas, tomemos a citação sobre o escritor Manuel Rui, que é "emprestado" como personagem em um dos sonhos "amarelotorrado" do menino-narrador: "até o TioRui que era escritor passava numa bicicleta que tinha uns bigodes desenhados e ele fazia as duas coisas, conduzia a bina e dominava o papagaio" (p. 77). Ao acamaradar um escritor como personagem, Ondjaki estabelece diálogos que o autenticam dentro do sistema literário e dão nós aos fios, visto que Manuel Rui tem um currículo "azul" invejável como precursor da temática do mar na literatura angolana do pósindependência.

Também vale ressaltar a descrição emblemática de EspumaDoMar, personagem (que como muitas outras desta narrativa) já havia figurado em uma primeira referência em Bom dia camaradas e em uma das estórias de Os da minha rua, sob o nome de Xana. O branco da espuma traça o contorno daquele que está entre o mar e o bairro, um indivíduo deslocado, mais lúmpen do que camarada:

- Não tenho banheira em casa, mas não podem dizer que nunca tomei banho de espuma.

O nome chegou assim, EspumaDoMar, ali na beirinha da praia da PraiaDoBispo, onde perto da areia o mar tinha uma mancha enorme de espumas brancas que aquela rebentaçãozinha inventava para a água chegar à areia sem ser com força, só andando muito é que se perdia o pé e a espuma desaparecia, mas ali perto, também onde nós gostávamos de apanhar conchas bonitas, era só espuma branca e limpa, olhando para a esquerda e para a direita, tudo branquinho, 
com o corpo do EspumaDoMar a fazer mancha escura na brancura da espuma do mar. (...) Uma pessoa que toma banho todos os dias a rir, a dizer que ali são os cabelos brancos do mar, uma pessoa que fala cubano e sabe das estrelas do céu e das matemáticas do valor do Pi e, quem sabe mesmo, uma pessoa com um jacaré na casota do cão, pode até ser uma pessoa feliz e só ele é que deve saber isso. O 3,14 fez assim com o dedo na testa a querer dizer que o Espuma era trololó, chanfru, maluco da cabeça, mas para dizer a verdade eu não sei se o Espuma era um maluco desses que toda a gente chama de maluco mesmo(p. 58-9).

O que se observa, quanto ao contexto desta digressão reminiscente, é que a tal figura vestida de trapos de poesia, o "maluco" não deixa o sendo da utopia, carrega as marcas de um país cujo regime político, na época monopartidário, não atendia a todos, mesmo que se propusesse:

- Tenho o corpo sujo, es verdad, pero mi alma está limpa... Nem todos podem dizer isso, no es así, lagostins? (...)

Às vezes tirava os panos do corpo e, por baixo, o EspumaDoMar tinha roupas antigas e sujas que nem dava para entender que tecidos eram aqueles. Outras vezes mergulhava com os panos pendurados no corpo, e não eram poucos, quando saía da água aquilo devia pesar um bocado (p. 57).

Pela janela da língua - as palavras internacionalistas-, o espanhol da fala de EspumaDoMar salienta a presença positiva dos cubanos em Luanda, destacada nesta narrativa pelo camarada médico RafaelTruzTruz. A mesma imagem não ocorre quanto aos soviéticos, que embora estejam em missão semelhante, falam uma língua ouvida como dura, distante e fria. O russo demora a ser língua de sonhar... só consegue em "segredo" de carta paratextual à narrativa já que para a personagem da AvóCatarina, o russo está "há dez anos aqui e nunca aprendeu o português de Angola. Estes soviéticos são uma vergonha do socialismo linguístico" (p. 27).

Dessa maneira, como quem se esgueira em meio à memória espremida do monopartidarismo, o narrador transforma o tempo em espaço de dialética. Os "gritos azuis" (p. 181) em eco, desde o início da narrativa, são retomados em meio à "desplosão" das obras do Mausoléu - durante este clímax, as crianças assistem ao espetáculo mergulhadas no mar, protegidas por esta pele azul, 
salpicadas de sal grosso, podem inventar à toa o futuro; mesmo que tenham que colocar pedras para marcar o lugar na fila do CamaradaPadeiro, mesmo que o VendedorDeGasolina não tenha água na mangueira e mesmo sabendo que "a guerra não deve ser nada como nos filmes porque o comando André quando vem a casa está cheio de fome e tão triste que não fala nada, só chora na hora que o camião vem lhe buscar" (p. 114).

Em epitexto, após a narrativa, temos além de um mapa-rascunho ${ }^{2}$ a carta à Ana Paula Tavares, a escritora angolana que, ao responder a Ondjaki, pactua com um outro trecho também de Clarice Lispector, só que do livro Legião estrangeira - o que parece bastante sugestivo considerando-se o segredo soviético do título: "O que eu quero é muito mais áspero e mais difícil, quero o terreno...", para isso Ana Paula Tavares não deixa de citar outros exploradores do terreno da poesia-mundo: Shakespeare, Cadornega e Ruy Duarte de Carvalho são retomados para tentar responder ao jovem escritor.

E entre "todos os azuis" (p. 168), a cor parece funcionar não só como pele, mas com um "tecto para Luanda" (p. 175) no seu "carnaval de cores" (p. 23) - debaixo dele dormem os camaradas, cujo valor de signo ideológico distingue os que compartilham o mesmo sono/sonho. Tons que talvez possam responder a pergunta do autor à Ana Paula Tavares: "Não é dessas paisagens, sobretudo, que o sonho trata?" (p. 194).

2 As citações utilizadas aqui referem-se à edição portuguesa. 